\title{
Failure by Immune Reaction to Metal Debris in Total J oint Arthroplasty of Hip and Knee
}

\author{
Boddu $\mathrm{C}^{1 *}$, Nett MP², Cushner FD $^{3}$ and \\ Scuderi $\mathbf{G R}^{4}$ \\ ${ }^{1}$ Clinical Fellow, NSLIJ Adult Reconstruction/Knee, \\ Lenox hill hospital, USA \\ ${ }^{2}$ Orthopedic Service Line, Northshore Long Island J ewish \\ Health System, USA \\ ${ }^{3}$ Chief of Orthopedics-Southside Hospital, USA \\ ${ }^{4}$ Program Director, Orthopedic Service Line, USA \\ *Correspondling author: Chandrakanth Boddu, \\ Clinical Fellow, NSLIJ Adult Reconstruction/ Knee, Lenox \\ hill hospital, USA
}

Received: November 03, 2016; Accepted: J anuary 12, 2017; Published: January 13, 2017

\begin{abstract}
Background: We propose a clinical classification for Failure by Immune Reaction to Metal debris (FIRM) in Total Joint Arthroplasty (TJA) of hip and knee. We also developed an evidence based diagnostic scoring system and estimated the treatment threshold for FIRM.

Methods: Pub Med and Embase search engines were used to identify original articles. We classified FIRM and identified the individual diagnostic criteria for each type of FIRM. For each individual diagnostic criterion we estimated the pooled Diagnostic Odds Ratio (DOR+) and the individual discriminatory FIRM (id FIRM) scores. From these scores total discriminatory FIRM (TdFIRM) scores were calculated.
\end{abstract}

Results: We identified a total of 39 original articles for meta-analysis. Based on predominant symptom of clinical presentation, we classified FIRM in

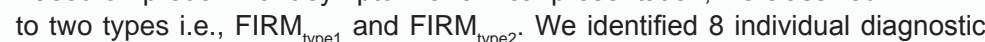
criteria for $\mathrm{FIRM}_{\mathrm{type1}}$ and FIRM $\mathrm{type}_{\text {and }}$ and for each type we estimated the pooled diagnostic odds ratio (DOR+) and the individual discriminatory FIRM (id FIRM) scores. TdFIRM score scores for FIRM $\mathrm{F}_{\mathrm{type} 1}$ and $\mathrm{FIRM}_{\mathrm{type2}}$ were 4.83 and 4.85 respectively. Treatment threshold for FIRM FIype1 $_{\text {trpe1 }}$ and FIRM $\mathrm{Ftype}_{\mathrm{type}}$ were estimated to be 3.38 and 3.39 respectively.

Conclusion: This meta-analysis provides a clinically useful tool for decision making when evaluating a patient suspected to have developed clinical complication by immune reaction to metal debris from arthroplasty. Future studies on FIRM should utilize this scoring system in decision making and critically evaluate its validity.

Keywords: Total joint arthroplasty; Osteolysis; Failure by immune reaction to metal debris; Metal allergy; Metal hypersensitivity

\section{Introduction}

The terms metal allergy and metal hypersensitivity are used interchangeably in the current literature to describe a spectrum of complications caused by immune reaction to metal debris generated in total joint arthroplasty. At one end of the spectrum is dermatitis. The dermatitis caused by immune reaction to metal debris may be new in onset or exacerbation of previous lesions and, can be localized or generalized manifestation.

At the other end of the spectrum is a consequence of local immune reaction to metal debris generated by total joint arthroplasty presenting clinically as a variable combination of pain in the joint, cystic lesions around the joint, aseptic loosening of implants and instability of the joint. Various terminologies exist to describe histopathological and imaging findings in patients with pain in the joint suspected to be from local reaction to metal debris after total joint arthroplasty. Willert et al termed the histopathological findings in these patients as Aseptic Lymphocyte-dominated Vasculitis-Associated Lesion (ALVAL) and LymphocYte-Dominated Immunological Answer (LYDIA) [1]. Another histopathological term 'Metallosis' was used by Korovessis et al to describe similar findings [2]. Pandit et al used the term 'Pseudotumour' to describe cystic and solid masses associated with resurfacing devices [3]. Longton et al described an umbrella term Adverse Reaction to Metal Debris (ARMD) to describe clinical failures of hip joint arthroplasty presenting with pain, a large sterile effusion and/or macroscopic necrosis [4].

For the purpose of this study, we used the acronym 'FIRM' (Failure by Immune Reaction to Metal debris) to describe all the clinical failures of Total Joint Arthroplasty (TJA) in hip and also knee joint due to immune reaction to metal debris. The objectives of this study are twofold. One is to develop a classification system for FIRM in TJA of hip and knee that is based on distinctive clinical manifestations. Second is to develop a diagnostic scoring system to facilitate the clinician to make an accurate, evidence based diagnosis.

\section{Materials and Methods}

In January 2015, a Pub Med and Embase search was performed independently using two search terms 'Metal Allergy Joint Replacement' (method 1) and 'Metal Hypersensitivity Joint Replacement' (method 2) for record identification. The search term that yielded the maximum number of results among the two was used for records identification from that particular search engine. The duplicates among Pub Med and Embase search were identified and removed. The selected records were screened by reviewing 


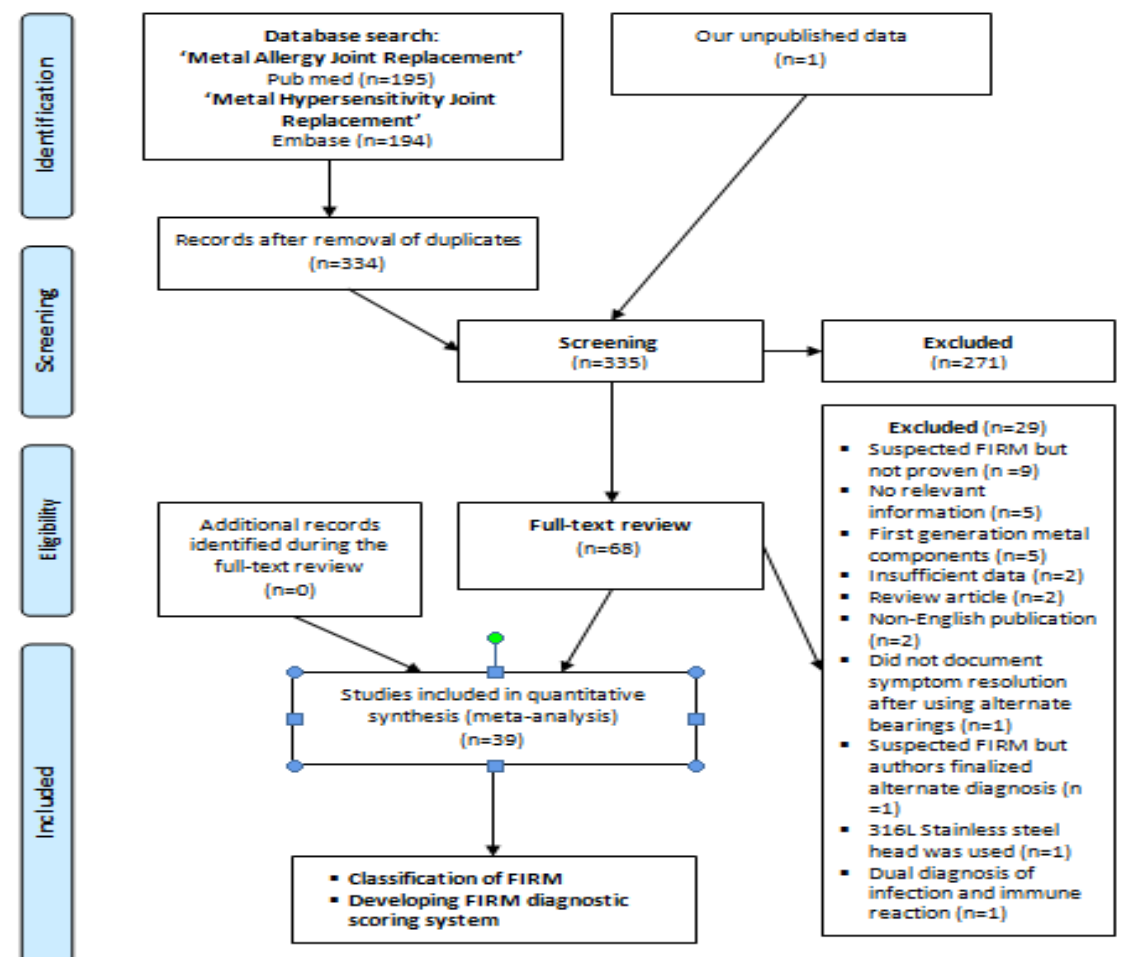

Figure 1: PRISMA Diagram showing the study flow from identification of original articles through meta-analysis.

Table 1: The clinical classification of total joint arthroplasty Failure by Immune Reaction to Metal ions (FIRM).

\begin{tabular}{|c|c|}
\hline FIRM $_{\text {Type } 1}$ & Presenting complication is predominantly dermatitis with minimal or no joint pain \\
\hline FIRM $_{\text {type1a }}$ & Localized cutaneous reaction (either new or exacerbation of previously existing lesion; located around the replaced joint or elsewhere) \\
\hline FIRM $_{\text {type1b }}$ & $\begin{array}{c}\text { Generalized cutaneous reaction (either new or exacerbation of previously existing lesions) } \\
\text { FIRM }_{\text {Type } 2}: \text { Presenting complication is predominantly painful joint effusion (with negative work-up of infection or neoplasm) with minimal or no } \\
\text { dermatitis }\end{array}$ \\
\hline FIRM $_{\text {type2a }}$ & Well fixed implants without evidence of osteolysis/cystic lesions \\
\hline FIRM $_{\text {type2b }}$ & Well fixed implants with evidence of osteolysis/cystic lesions \\
\hline FIRM $_{\text {type2c }}$ & Aseptic loosening of component(s) \\
\hline FIRM $_{\text {type2d }}$ & Instability/Dislocation of the joint \\
\hline
\end{tabular}

the abstract for clinical data on TJA patients with FIRM and were included for full-text review. If abstract is not available for a record, it was selected for full-text review by default. Of all the records selected for full-text review, final analysis included only the articles with clinical data on TJA patients with FIRM who had a negative work-up for the possibility of infection or neoplasm (primary or metastatic) and could successfully be managed by removal of implants and reinsertion of new implants that generate no metal debris or by pseudoarthrosis (positive control). In addition, we looked carefully to identify such additional records which we may have missed during Pub Med or Embase search but have the data that we are interested in by reviewing the references section of all the full-text reviewed records and if such record is found, was included in the systematic review and meta analysis.

\section{Part I: FIRM clinical classification}

By systematic review of the articles selected for final analysis, we identified all the described complications due to FIRM in patients with TJA and grouped them depending on the most commonly observed patterns of clinical presentation.

\section{Part II: FIRM diagnostic scoring system}

A meta-analysis was performed to develop FIRM scoring system using the data from the full-text reviewed records. The first step was calculation of pooled diagnostic odds ratio (also called likelihood ratio) of all the individual diagnostic criteria for each defined type of FIRM $_{\text {type } 1 \text { to } n}$ using the formula,

$\mathrm{DOR}+=$ (Most commonly observed result of a diagnostic criteria +0.5$) /($ Least commonly observed result of a diagnostic criteria+0.5).

Where, DOR+ is the pooled diagnostic odds ratio of a positive result. Addition of 0.5 to all counts is a validated statistical method to obtain a definable value of DOR+. Individual discriminatory FIRM score of each diagnostic criterion (idFIRM cl to n $_{n}$ ) for FIRM type 1 to n $_{\text {was }}$ derived by converting its linear $\mathrm{DOR}+$ value in to logarithmic value. 
Table 2: The results of meta-analysis of FIRM $_{\text {type } 1}$ diagnostic criteria.

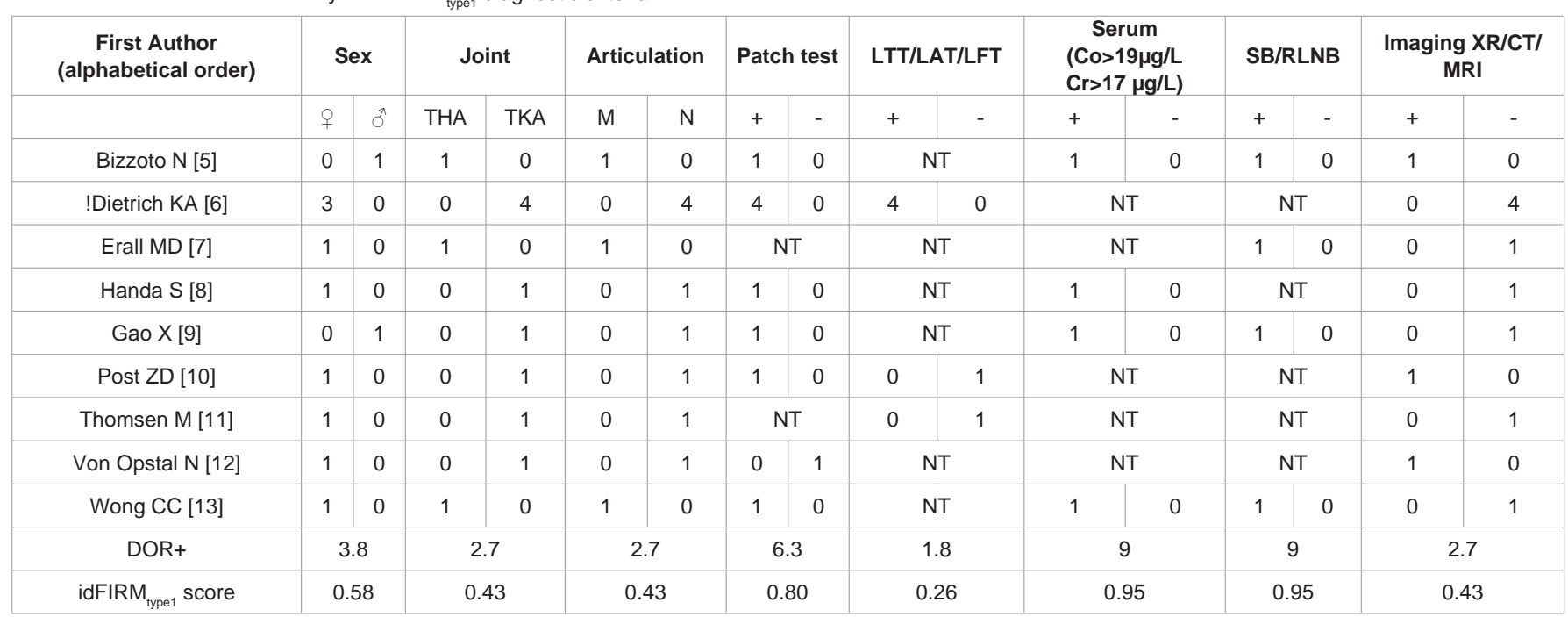

LTT/LAT/LFT Lymphocyte Transformation Test(s)/Lymphocyte Activation Test(s)/ Lymphocyte Function Test(s); SB/RLNB: Skin Biopsy/ Regional Lymph Node Biopsy; XR/CT/MRI: X-rays/Computerized Tomography/Magnetic Resonance Imaging; THA: Total Hip Arthroplasty; TKA: Total Knee Arthroplasty; M: Hip or knee implant with Metal on Metal bearings or implants with Mores taper between two modular CoCr components

N Hip or knee implant with CoCr component but has no Metal on Metal bearings or Mores taper between two modular CoCr components; NT: Not Tested ! Only 3 patient's gender was described among the 4 total reported cases.

Table 3: The diagnostic scoring system for FIRM type1 $_{1}$ is represented below.

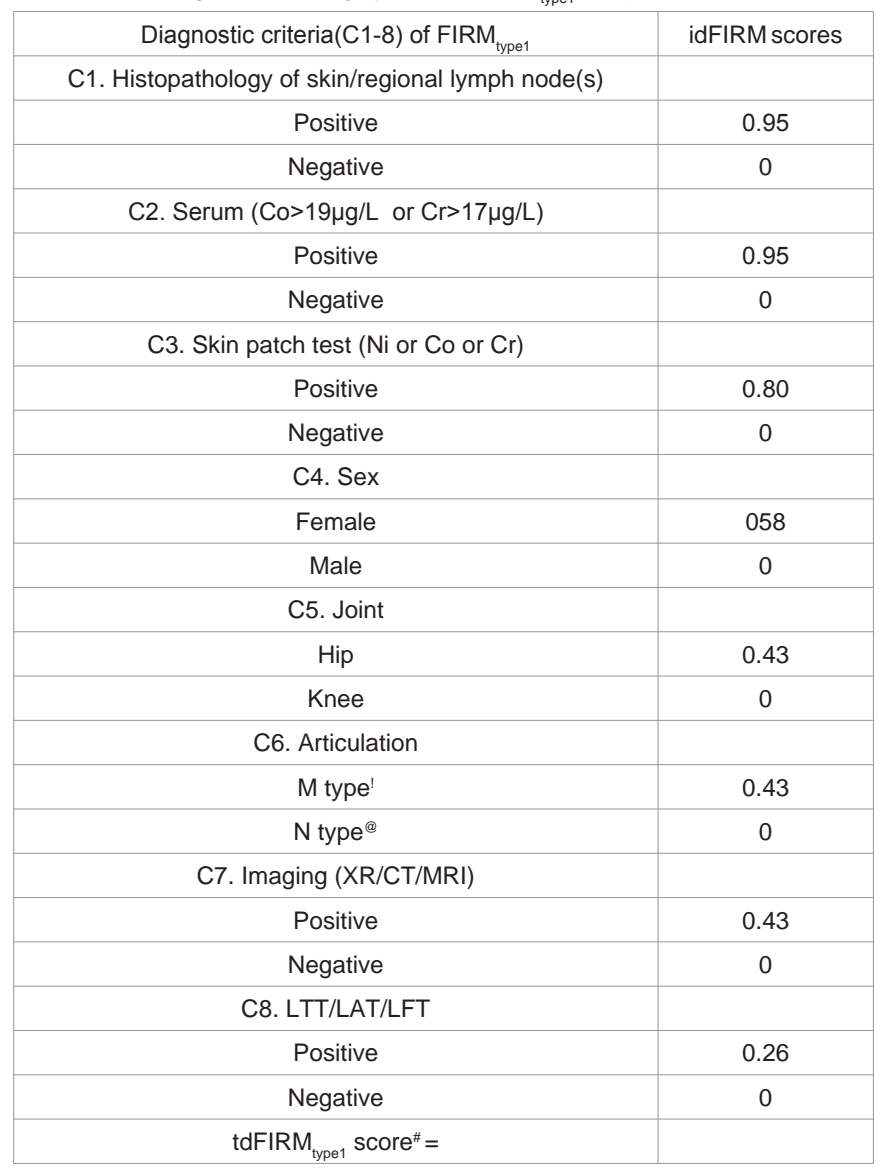

!M type Hip or knee implant with Metal on Metal bearings or implants with Mores taper between two modular CoCr components; @N type: Hip or knee implant with $\mathrm{CoCr}$ component but has no Metal on Metal bearings or Mores taper between two modular CoCr components; LTT/LAT/LFT: Lymphocyte Transformation Test(s)/Lymphocyte Activation Test(s)/Lymphocyte Function Test(s); \#: The recommended cutoff value for the treatment threshold is 3.38 .
If all the individual diagnostic criteria identified for FIRM type 1 to n $_{\text {are }}$ perfectly independent of each other, the total discriminatory FIRM score of FIRM type 1 to $n_{\text {that }}$ thould determine the treatment threshold for revision surgery can be mathematically be expressed as,

$$
\text { tdFIRM }_{\text {type } 1 \text { to } n}=\text { idFIRM }_{\mathrm{c} 1}+\operatorname{idFIRM}_{\mathrm{c} 2} \ldots \ldots .+ \text { idFIRM }_{\mathrm{cn}}
$$

Where, $t$ dFIRM $M_{\text {type 1 ton }}$ is the total discriminatory score of FIRM to $n$ (in logarithmic scale), $i d F I R M_{\mathrm{cl}}$ is the individual discriminatory FIRM score of a diagnostic criteria $\mathrm{cl}$ for FIRM type 1 ton $_{\text {(in logarithmic }}$ scale), and so on. If we found that the individual diagnostic criteria identified for FIRM ${ }_{\text {type } 1 \text { to } n}$ were partially independent of each other, we decided to fix the treatment threshold for revision surgery at $70 \%$ of the calculated tdFIRM ${ }_{\text {typel to } n}$ for FIRM typel to $n$.

\section{Results}

When Pub Med and Embase were searched as per method 1 using the term 'Metal Allergy Joint Replacement' without applying any other filters, 195 and 76 articles were identified respectively. When a similar search was conducted as per method 2 using the term 'Metal Hypersensitivity Joint Replacement', 178 and 194 articles were identified in Pub Med and Embase respectively. The term that yielded maximum number of results among the two search terms was selected for record identification and abstract review. After removing the duplicates there were 334 articles available for screening of abstracts (Figure 1). When we included our unpublished record (MPN), we had a total of 335 records available for screening. We excluded 271 records among the final 335 that were screened, as they were not relevant to answer this study objective. We full text reviewed the remaining 68 records among the 335 records that were screened. Out of 68 records that were full text reviewed, 29 records were excluded for various reasons. Hence we identified a total of 39 original articles with data relevant to this study. During the process of full text review of these 39 records, we could not identify any additional original articles that were not previously identified by either Pub Med or 
Table 4: The results of meta-analysis of FIRM $_{\text {type2 }}$ diagnostic criteria.

\begin{tabular}{|c|c|c|c|c|c|c|c|c|c|c|c|c|c|c|c|c|}
\hline \multirow[t]{2}{*}{$\begin{array}{c}\text { First Author (alphabetical } \\
\text { order) }\end{array}$} & \multicolumn{2}{|c|}{ Sex } & \multicolumn{2}{|c|}{ Joint } & \multicolumn{2}{|c|}{ Articulation } & \multicolumn{2}{|c|}{$\begin{array}{l}\text { Patch test } \\
\text { (Co,Cr,Ni) }\end{array}$} & \multicolumn{2}{|c|}{ LTT/LAT } & \multicolumn{2}{|c|}{$\begin{array}{c}\text { Serum } \\
(\mathrm{Co}>19 \mu \mathrm{g} / \mathrm{L} \\
\mathrm{Cr}>17 \mu \mathrm{g} / \mathrm{L})\end{array}$} & \multicolumn{2}{|c|}{ HP } & \multicolumn{2}{|c|}{$\begin{array}{c}\text { Imaging (XR/CTI } \\
\text { MRI) }\end{array}$} \\
\hline & q & $\partial^{2}$ & THA & TKA & M & $\mathrm{N}$ & + & - & + & - & + & - & + & - & + & - \\
\hline Anand A [14] & 0 & 1 & 0 & 1 & 0 & 1 & 1 & 0 & \multicolumn{2}{|c|}{ NT } & \multicolumn{2}{|c|}{ NT } & 1 & 0 & 1 & 0 \\
\hline Bergschmidt P [15] & 1 & 0 & 0 & 1 & 0 & 1 & 1 & 0 & \multicolumn{2}{|c|}{ NT } & \multicolumn{2}{|c|}{ NT } & 1 & 0 & 0 & 1 \\
\hline Bernasek TL [16] & \multicolumn{2}{|c|}{ ND } & 2 & 0 & 2 & 0 & \multicolumn{2}{|c|}{ NT } & \multicolumn{2}{|c|}{ NT } & 1 & 1 & 1 & 1 & 0 & 2 \\
\hline Blumenfeld TJ [17] & 1 & 0 & 1 & 0 & 1 & 0 & \multicolumn{2}{|c|}{ NT } & & & \multicolumn{2}{|c|}{ NT } & 1 & 0 & 0 & 1 \\
\hline Campbell P [18] & 4 & 1 & 5 & 0 & 5 & 0 & \multicolumn{2}{|c|}{ NT } & & & \multicolumn{2}{|c|}{ NT } & 5 & 0 & 4 & 1 \\
\hline Carr AM [19] & 2 & 1 & 3 & 0 & 3 & 0 & \multicolumn{2}{|c|}{ NT } & & & \multicolumn{2}{|c|}{ NT } & 3 & 0 & 3 & 0 \\
\hline Engh CA Jr [20] & \multicolumn{2}{|c|}{ ND } & 1 & 0 & 1 & 0 & \multicolumn{2}{|c|}{ NT } & & & & & 1 & 0 & & \\
\hline Jensen P [21] & 1 & 0 & 1 & 0 & 1 & 0 & 1 & 0 & & & & & 1 & 0 & 1 & 0 \\
\hline Kemp MA [22] & 3 & 0 & 3 & 0 & 3 & 0 & & & & & & & 3 & 0 & 3 & 0 \\
\hline Korovessis P [2] & & & 9 & 0 & 9 & 0 & & & & & & & 9 & 0 & 9 & 0 \\
\hline Kosukegawa [24] & 1 & 0 & 1 & 0 & 1 & 0 & & & & & & & 1 & 0 & 1 & 0 \\
\hline Kumar [25] & 1 & 1 & 2 & 0 & 2 & 0 & 2 & 0 & & & 1 & 0 & 1 & 0 & 2 & 0 \\
\hline Lohmann CH [26] & 24 & 3 & 27 & 0 & 27 & 0 & & & & & 17 & 10 & 15 & 13 & 20 & 7 \\
\hline Mahendra G [27] & & & 30 & 0 & 30 & 0 & & & & & & & 30 & 0 & 25 & 5 \\
\hline Melosev I [28] & & & 25 & 0 & 25 & 0 & & & & & & & 13 & 4 & 16 & 9 \\
\hline Mikhael MM [29] & 0 & 2 & 2 & 0 & 2 & 0 & & & 1 & 0 & 0 & 1 & 1 & 0 & 0 & 2 \\
\hline Mc Master WC [30] & 0 & 1 & 0 & 1 & 1 & 0 & & & 0 & 1 & 1 & 0 & 1 & 0 & 0 & 1 \\
\hline @Nett MP & 0 & 2 & 2 & 0 & 2 & 0 & & & & & 0 & 2 & 2 & 0 & 2 & 0 \\
\hline Pandit H & 13 & 0 & 13 & 0 & 13 & 0 & & & & & & & 13 & 0 & 10 & 3 \\
\hline Roessler PP [33] & 0 & 1 & 1 & 0 & 1 & 0 & 1 & 0 & & & 0 & 1 & 1 & 0 & 1 & 0 \\
\hline Singh C [34] & 1 & 0 & 1 & 0 & 1 & 0 & & & & & & & 1 & 0 & 1 & 0 \\
\hline Thakur RR [35] & 4 & 1 & 0 & 5 & 0 & 5 & 2 & 2 & & & & & 5 & 0 & 2 & 3 \\
\hline Theruvil B [36] & 3 & 0 & 3 & 0 & 3 & 0 & & & & & & & 3 & 0 & 3 & 0 \\
\hline Thomas P [37] & 8 & 8 & 16 & 0 & 16 & 0 & 10 & 6 & 8 & 8 & & & 16 & 0 & 8 & 8 \\
\hline Toms AP [38] & 0 & 1 & 1 & 0 & 1 & 0 & & & & & & & 1 & 0 & 1 & 0 \\
\hline Viveganathan B [39] & 1 & 0 & 0 & 1 & 0 & 1 & 1 & 0 & & & & & NT & & 1 & 0 \\
\hline "Willert HG & 9 & 10 & 19 & 0 & 19 & 0 & & & & & & & 19 & 0 & 12 & 5 \\
\hline DOR+ & & & & & & & & & & & & & & & & \\
\hline idFIRM type2 $_{2}$ score & & & & & & & & & & & & & & & & \\
\hline
\end{tabular}

LTT/LAT/LFT: Lymphocyte Transformation Test(s)/Lymphocyte Activation Test(s)/Lymphocyte Function Test(s); HP: Histopathology of joint tissue; XR/CT/MRI: X-rays/Computerized Tomography/ Magnetic Resonance Imaging; THA: Total Hip Arthroplasty TKA Total Knee Arthroplasty; M: Hip or knee implant with Metal on Metal bearings or implants with Mores taper between two modular $\mathrm{CoCr}$ components; $\mathrm{N}$ : Hip or knee implant with CoCr component but has no Metal on Metal bearings or Mores taper between two modular CoCr components, NT: Not Tested; ND: No Data; 'Of the three reported cases, one case not included because of dual diagnosis of infection and immune reaction to metal ions; @: Unpublished data of author (MPN); \#: Histopathology finding were not reported in 2 among the total of 19 patients.

Embase search but had the clinical data on FIRM in patients with TJA. Hence, we had a total of 39 articles available for meta-analysis.

\section{Part I: FIRM clinical classification}

Based on predominant symptom of clinical presentation, we classified FIRM in to two types i.e., FIRM $_{\text {type1 }}$ and FIRM type2 (Table 1). Further subclassification of cutaneous reaction was attempted based on the location of skin lesions i.e., localized or generalized. Similarly, subclassification of painful joint effusions was attempted based on further clinical qualifiers i.e., evidence of osteolysis or component loosening or dislocation.

\section{Part II: FIRM diagnostic scoring system}

Nine among the 39 articles selected for final analysis had data on FIRM $_{\text {typel }}$ (Table 2). A total of 12 joints that developed FIRM were identified among these 9 articles. We identified 8 individual 
Table 5: The diagnostic scoring system for FIRM $\mathrm{F}_{\text {type2 }}$ is represented below.

\begin{tabular}{|c|c|}
\hline Diagnostic criteria(C1-7) of FIRM $\mathrm{Type}_{\mathrm{typ}}$ & idFIRM score \\
\hline \multicolumn{2}{|l|}{ C1. Joint } \\
\hline Hip & 1.32 \\
\hline Knee & 0 \\
\hline \multicolumn{2}{|l|}{ C2. Articulation } \\
\hline M type! & 1.32 \\
\hline N type ${ }^{@}$ & 0 \\
\hline \multicolumn{2}{|l|}{ C3. Histopathology from the joint tissue } \\
\hline Positive & 0.91 \\
\hline Negative & 0 \\
\hline \multicolumn{2}{|l|}{ C4. Imaging (XR/CT/MRI) } \\
\hline Positive & 0.41 \\
\hline Negative & 0 \\
\hline \multicolumn{2}{|l|}{ C5. Sex } \\
\hline Female & 0.36 \\
\hline Male & 0 \\
\hline \multicolumn{2}{|l|}{ C6. Skin patch test (Ni or Co or $\mathrm{Cr}$ ) } \\
\hline Positive & 0.36 \\
\hline Negative & 0 \\
\hline \multicolumn{2}{|l|}{ C7 Serum $(\mathrm{Co}>19 \mu \mathrm{g} / \mathrm{L}$ or $\mathrm{Cr}>17 \mu \mathrm{g} / \mathrm{L})$} \\
\hline Positive & 0.17 \\
\hline Negative & 0 \\
\hline tdFIRM $_{\text {type } 2}$ score $^{\#}=$ & \\
\hline
\end{tabular}

!: M type Hip or knee implant with Metal on Metal bearings or implants with Mores taper between two modular CoCr components; @ N type: Hip or knee implant with $\mathrm{CoCr}$ component but has no Metal on Metal bearings or Mores taper between two modular $\mathrm{CoCr}$ components; LTT/LAT/LFT: Lymphocyte Transformation Test(s) /Lymphocyte Activation Test(s)/Lymphocyte Function Test(s); \#: The recommended cutoff value for the treatment threshold is 3.39 .

diagnostic criteria that were at least partially independent of each other. When we tested the statistical weight of these 8 individual diagnostic criteria, we identified that all are useful for diagnosis of FIRM $_{\text {typel }}$, but the contribution of each to the identified FIRM

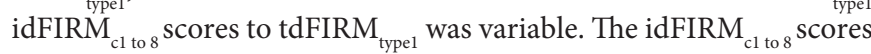
of FIRM $_{\text {typel }}$ are represented in descending of their statistical weight in (Table 3). The estimated tdFIRM ${ }_{\text {typel }}$ score of the FIRM type1 $_{\text {tiagnostic }}$ criteria was 4.83. As the identified individual diagnostic criteria were partially independent, the treatment threshold for revision surgery was estimated to be 3.38 i.e., $70 \%$ of 4.83 .

Thirty among the 39 articles selected for final analysis had data on FIRM $_{\text {type } 2}$ (Table 4). A total of 177 joints that developed FIRM type $2_{2}$ were identified among these 30 articles. We identified 8 individual diagnostic criteria that were partially independent of each other. When we tested the statistical weight of these 8 individual diagnostic criteria, with the exception of lymphocyte function testing, the rest were found to be useful for diagnostic purpose. The contribution of each to the identified FIRM type $2_{\text {idFIRM }}$ c1 to $7_{\text {scores to tdFIRM }}$ type2 was also variable. Interestingly, the contribution of each to the identified FIRM $_{\text {typel }}$ idFIRM $_{c 1 \text { to } 8}$ scores to tdFIRM $M_{\text {typel }}$ score was different from the contribution of FIRM $_{\text {type } 2}$ idFIRM $_{\mathrm{cl} \text { to } 7}$ scores to the tdFIRM $_{\text {type2 }}$ score. The idFIRM ${ }_{\text {c1 to } 7}$ scores of FIRM $_{\text {type } 2}$ are represented in descending of their statistical weight in (Table 5). The estimated

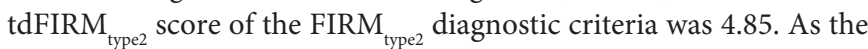
identified individual diagnostic criteria were partially independent, the treatment threshold for revision surgery was estimated to be 3.39 i.e., $70 \%$ of 4.85 .

\section{Discussion}

\section{Significance of the study}

This is the first proposed comprehensive classification system of FIRM in patients with either THA or TKA that identified and statistical weighed the strength of individual diagnostic criteria, developed of a clinically applicable diagnostic scoring system and estimated a threshold level for the revision surgery.

\section{Concerns}

There are three specific concerns that we should address in detail regarding the methodology used in this meta-analysis. First, is the use of DOR+ (also called Likelihood ratio) as a single indicator of a diagnostic criterion's performance compared to the traditional paired indices of test validity such as predictive values. The attractive features of likelihood ratios that are not shared by the predictive values are applicability to specific patient rather than relate test results to populations, applicability across the disease frequencies and ability to combine the tests in order to refine the clinical judgment [40].

Second issue concerning the methodology is to provide an explanation for use of logarithmic scale than a more familiar linear scale. The best way to estimate the strength of a differentially used diagnostic criteria across the studies is to convert linear scores in to logarithmic scores so that, the plotted score-treatment threshold curve will be changed from hyperbolic to sigmoid curve where usually, between $25 \%$ to $75 \%$ of the maximum response, the relation between the diagnostic scoring system and the treatment threshold will be linear, so that a better understanding and interpretation is possible. In other words, if all the included studies for meta-analysis did used exactly the same set of diagnostic criteria for decision making in all their cases, there would have been no need to convert the linear scores into logarithmic scale.

Third and the most important issue concerning this scoring system is the selection of $70 \%$ of tdFIRM score as the treatment threshold. Nomogram created for the Bayes theorem indicates that an odds ratio of 10 to 1,100 to 1 and 1000 to 1 are equivalent to a post-test probability of $50 \%, 75 \%$ and $>95 \%$ respectively [41]. As the minimum required tdFIRM typel $_{\text {and }}$ adFIRM type 2 score for treating threshold is considered 3.38 and 3.39 respectively, the odds of being correct is more than 2000 to 1 or a post-test probability of approximately $99 \%$.

\section{Clinical application}

It is important to understand that though 7 out of 8 tested diagnostic criteria for FIRM typel $_{\text {and }}$ FIRM type2 $_{\text {are the same, their }}$ contribution to their respective tdFIRM score is different based on the strength of the odds ratio of each individual diagnostic criteria. The gender of the patient, the joint under evaluation and availability of previous surgical records provides pre-test tdFIRM score for a patient under evaluation for FIRM. Depending on the pre-test tdFIRM score, this scoring system provides clinicians with flexibility to decide which among the 5 tests (Histopathology/Imaging/Path test/Serum 
Table 6: Etiology and pathogenesis of FIRM in patients with total joint arthroplasty.

\begin{tabular}{|c|c|c|c|}
\hline & Type1 FIRM & \multicolumn{2}{|l|}{ Type2 FIRM } \\
\hline Principle stimulus & $\mathrm{Ni}$ & \multicolumn{2}{|l|}{$\mathrm{Co}, \mathrm{Cr}$} \\
\hline Particle size & Sub micrometer & Sub nanometer & Sub micrometer \\
\hline Joint tissue metal content & Not known & $\uparrow$ & $\uparrow \uparrow$ \\
\hline Joint metal ion level & Not known & $\uparrow \uparrow$ & $\uparrow$ \\
\hline Serum metal ion level & $\uparrow \uparrow$ & $\uparrow \uparrow$ & $\uparrow$ \\
\hline Interaction with APC & Extra cellular & Intracellular & Extra cellular \\
\hline Pathway & $\mathrm{T}_{\mathrm{h} 17}$ inflammation & $\mathrm{T}_{\mathrm{h} 1}$ inflammation & $\mathrm{T}_{\mathrm{h} 17}$ inflammation \\
\hline Helper T cells & $\mathrm{T}_{\mathrm{h} 17}$ cell & $\mathrm{T}_{\mathrm{h} 1}$ cell & $\mathrm{T}_{\mathrm{h} 17}$ cell \\
\hline Cytokine mediator & IL-17 & INF-Y & IL-17 \\
\hline Effector cells & Activated CTLs & Activated Macrophage & Activated CTLs \\
\hline Histological appearance & PVLI, DLI & Coagulative necrosis & PVLI, DLI \\
\hline Clinical effect & $\begin{array}{c}\text { Synovitis (=pain/effusion) } \\
\text { Dermatitis }\end{array}$ & Osteolysis (= pseudo tumors, aseptic loosening) & Synovitis (=pain/effusion) \\
\hline
\end{tabular}

ion level/Lymphocyte based tests) to perform to either rule in or rule out a possibility of reaching the treatment threshold value of tdFIRM. For example, a male patient with total knee arthroplasty with an $\mathrm{N}$ type implant under evaluation for suspected FIRM $_{\text {typel }}$ has a pre-test score of zero. To make a diagnosis of FIRM typel $_{1}$ in him all the 5 tests need to be positive to cross the treatment threshold of 3.38. On the contrary, a female patient with total hip arthroplasty with an $\mathrm{M}$ type implant under evaluation for suspected FIRM ${ }_{\text {type2 }}$ has a pre-test score of 3. Hence, she would reach a treatment threshold of 3.39 if either histopathology or imaging is positive. If the imaging is negative for her and the clinician would like to reserve histopathology as the last resort for diagnosis as it is an operative procedure, treatment threshold can be reached with a positive patch test and positive serum metal ion levels.

\section{Conclusion}

This meta-analysis provides a clinically useful tool for decision making when evaluating a patient suspected to have developed clinical complication by immune reaction to metal debris from arthroplasty. Future studies on FIRM should utilize this scoring system in decision making and critically evaluate its validity.

\section{References}

1. Willert HG, Buchhorn GH, Fayyazi A. Metal-on-metal bearings and hypersensitivity in patients with artificial hip joints. A clinical and histomorphological study. J Bone Joint Surg Am. 2005; 87: 28.

2. Korovessis P, Petsinis G, Repanti M. Metallosis after contemporary Metal-onMetal total hip arthroplasty: Five to seven year follow up. J Bone Joint Surg Am. 2006; 88: 1183.

3. Pandit H, Glyn-Jones S, McLardy-Smith P. Pseudotumour associated with metal-on-metal hip resurfacings. J Bone Joint Surg [Br]. 2008; 90: 847.

4. Langton DJ, Jameson SS, Joyce TJ. Early failure of metal-on-metal bearings in hip resurfacing and large-diameter total hip replacement: a consequence of excess wear. J Bone Joint Surg (Br). 2010; 92: 38.

5. Bizzotto N, Sandri A, Trivellin G. Chromium-Induced Diffuse Dermatitis and Lymph Node Involvement by Langerhans Cell Histiocytosis After Metal-onMetal Hip Resurfacing. Br J Dermatol. 2014.

6. Dietrich KA, Mazoochian F, Summer B. Intolerance reactions to knee arthroplasty in patients with nickel/cobalt allergy and disappearance of symptoms after revision surgery with titanium-based endoprostheses. J Dtsch Dermatol Ges. 2009; 7: 410.
7. Earll MD, Earll PG, Rougeux RS. Wound drainage after metal-on-metal hip arthroplasty secondary to presumed delayed hypersensitivity reaction. J Arthroplasty. 2011; 26: 338.e5.

8. Handa S, Dogra S, Prasad R. Metal sensitivity in a patient with a total knee replacement. Contact Dermatitis. 2003; 49: 259.

9. Gao X, He RX, Yan SG. Dermatitis associated with chromium following total knee arthroplasty. J Arthroplasty. 2011; 26: 665.e13.

10. Post ZD, Orozco FR, Ong AC. Metal sensitivity after TKA presenting with systemic dermatitis and hair loss. Orthopedics. 2013; 36: e525.

11. Thomsen M, Rozak M, Thomas P. Pain in a chromium-allergic patient with total knee arthroplasty: disappearance of symptoms after revision with a special surface-coated TKA--a case report. Acta Orthop. 2011; 82: 386.

12. Van Opstal N, Verheyden F. Revision of a tibial baseplate using a customized oxinium component in a case of suspected metal allergy. A case report. Acta Orthop Belg. 2011; 77: 691.

13. Wong CC, Nixon RL. Systemic allergic dermatitis caused by cobalt and cobalt toxicity from a metal on a metal hip replacement. Contact Dermatitis. 2014; 71: 113.

14. Anand A, McGlynn F, Jiranek W. Metal hypersensitivity: can it mimic infection? J Arthroplasty. 2009; 24: 826.e25.

15. Bergschmidt P, Bader R, Mittelmeier W. Metal hypersensitivity in total knee arthroplasty: revision surgery using a ceramic femoral component - a case report. Knee. 2012; 19: 144

16. Bernasek TL, Polikandriotis JA, Levering MF, et al. Five- to ten-year outcomes for modular metal-on-metal total hip arthroplasty. J Arthroplasty. 2013; 28: 1231.

17. Blumenfeld TJ, Bargar WL, Campbell PA. A painful metal-on-metal total hip arthroplasty: a diagnostic dilemma. J Arthroplasty. 2010; 25: 1168. e1.

18. Campbell $P$, Shimmin A, Walter $L$, et al. Metal sensitivity as a cause of groin pain in metal-on-metal hip resurfacing. J Arthroplasty. 2008; 23: 1080.

19. Carr AM, DeSteiger R. Osteolysis in patients with a metal-on-metal hip arthroplasty. ANZ J Surg. 2008; 78: 144.

20. Engh CA Jr, Ho H, Engh CA. Metal-on-metal hip arthroplasty: does early clinical outcome justify the chance of an adverse local tissue reaction? Clin Orthop Relat Res. 2010; 468: 406.

21. Jensen P, Thyssen JP, Retpen JB. Cobalt allergy and suspected aseptic lymphocyte-dominated vascular-associated lesion following total hip arthroplasty. Contact Dermatitis. 2009; 61: 238.

22. Kemp MA, Mitra A, da Costa TM. Bearing exchange in the management of Pseudotumour. Ann R Coll Surg Engl. 2013; 95: 266. 
23. Kiran M, Boscainos PJ. Adverse reactions to metal debris in metal-onpolyethylene total hip arthroplasty using a titanium-molybdenum-zirconiumiron alloy stem. J Arthroplasty. 2015; 30: 277.

24. Kosukegawa I, Nagoya S, Kaya M, et al. Revision total hip arthroplasty due to pain from hypersensitivity to cobalt-chromium in total hip arthroplasty. J Arthroplasty. 2011; 26: 978. e1.

25. Kumar P, Bryan C, Bowler J. Fialed total knee prosthesis secondary to metal hypersensitivity. Orthopaedics. 1983; 6: 1459.

26. Lohmann $\mathrm{CH}$, Meyer $\mathrm{H}$, Nuechtern JV. Periprosthetic tissue metal conten but not serum metal content predicts the type of tissue response in failed small-diameter metal-on-metal total hip arthroplasties. J Bone Joint Surg Am. 2013; 95: 1561.

27. Mahendra G, Pandit H, Kliskey K. Necrotic and inflammatory changes in metal-on-metal resurfacing hip arthroplasties. Acta Orthop. 2009; 80: 653.

28. Milosev I, Trebse R, Kovac S, et al. Survivorship and retrieval analysis of Sikomet metal-on-metal total hip replacements at a mean of seven years. $J$ Bone Joint Surg Am. 2006; 88: 1173.

29. Mikhael MM, Hanssen AD, Sierra RJ. Failure of metal-on-metal total hip arthroplasty mimicking hip infection. A report of two cases. J Bone Joint Surg Am. 2009; 91: 443

30. McMaster WC, Patel J. Adverse local tissue response lesion of the knee associated with Morse taper corrosion. J Arthroplasty. 2013; 28: 375.e5.

31. Perumal V, Alkire M, Swank ML. Unusual presentation of cobal hypersensitivity in a patient with a metal-on-metal bearing in total hip arthroplasty. Am J Orthop (Belle Mead NJ). 2010; 39: E39.

32. Rajpura A, Porter ML, Gambhir AK. Clinical experience of revision of metal on metal hip arthroplasty for aseptic lymphocyte dominated vasculitis associated lesions (ALVAL). Hip Int 2011; 21: 43.
33. Roessler PP, Witt F, Efe T. Arthroprosthetic cobaltism and pseudotumour also occur in patients with small diameter femoral ball head metal-on-meta total hip arthroplasties. BMJ Case Rep. 2014

34. Singh C, Kaplan A, Pambuccian SE. Necrotic granulomatous pseudotumor following metal-on-metal hip arthroplasty: a potential mimic of sarcoma on fine needle aspiration cytology. Diagn Cytopathol. 2012; 40: E104.

35. Thakur RR, Ast MP, McGraw M. Severe persistent synovitis after cobaltchromium total knee arthroplasty requiring revision. Orthopedics. 2013; 36 : e520.

36. Theruvil B, Vasukutty N, Hancock N. Dislocation of large diameter metal-onmetal bearings an indicator of metal reaction? J Arthroplasty. 2011; 26: 832.

37. Thomas P, Braathen LR, Dörig M. Increased metal allergy in patients with failed metal-on-metal hip arthroplasty and peri-implant T-lymphocytic inflammation. Allergy. 2009; 64: 1157

38. Toms AP, Nolan J, Barker T. Early failure of a Birmingham resurfacing hip replacement with lymphoreticular spread of metal debris: pre-operative diagnosis with MR. Br J Radiol. 2009; 82: 977.e87.

39. Vivegananthan B, Shah R, Karuppiah AS. Metallosis in a total knee arthroplasty. BMJ case rep. 2014.

40. Grimes DA, Schulz KF. Uses and abuses of screening tests. Lancet. 2002; 359: 881.

41. Fagan TJ. Letter: nomogram for Bayes theorem. N Engl J Med. 1975; 293: 257.
Austin J Musculoskelet Disord - Volume 4 Issue 1 - 2017

ISSN : 2381-8948 | www.austinpublishinggroup.com

Boddu et al. (C) All rights are reserved
Citation: Boddu C, Nett MP, Cushner FD and Scuderi GR. Failure by Immune Reaction to Metal Debris in Total Joint Arthroplasty of Hip and Knee. Austin J Musculoskelet Disord. 2017; 4(1): 1038. 